\title{
Gastrointestinal manifestations associated with systemic sclerosis: results from the nationwide inpatient sample
}

\author{
Yaseen Alastala, Tariq A. Hammada, Anas Renno ${ }^{a}$, Basmah Khalila, , Joel Pierre $^{\mathrm{b}}$, Bismark Kwaah ${ }^{\mathrm{b}}$, \\ Sadik A. Khuderb, Ali Nawras ${ }^{a}$
}

University of Toledo, Toledo, OH, USA

\section{Abstract}

\section{Introduction}

Systemic sclerosis (SSc) is a multisystemic autoimmune disease characterized by progressive and systemic

Departments of anternal Medicine, Division of Gastroenterology (Yaseen Alastal, Tariq A. Hammad, Anas Renno, Basmah Khalil, Ali Nawras); bPublic Health and Preventive Medicine (Joel Pierre, Bismark Kwaah, Sadik A. Khuder), University of Toledo, Toledo, OH, USA

\section{Conflict of Interest: None}

Correspondence to: Dr. Anas Renno, University of Toledo Medical Center, Department of Internal Medicine, 3000 Arlington Avenue, Toledo, OH 43614, USA, Tel.: +1 419383 6810, Fax: +1 419383 6180, e-mail: anas.renno@utoledo.edu

Received 12 April 2017; accepted 24 May 2017; published online 30 June 2017

DOI: https://doi.org/10.20524/aog.2017.0171 deposition of connective tissue in the skin and internal organs. The estimated prevalence of SSc in the United States is around 240 cases per 1 million adults [1]. The gastrointestinal (GI) tract is the most common site of visceral involvement and the esophagus is the organ most commonly affected by the disease [2]. GI involvement in SSc has been estimated to be approximately 70-90\% [3,4]. Patients present with a wide variety of symptoms depending on the site of involvement. GI involvement carries a significant morbidity and may adversely impact the quality of life in patients with SSc. Multiple studies investigated the prevalence of upper GI manifestations in SSc patients, but other GI manifestations were only reported in a few case reports or small retrospective studies. In this study, we investigated the prevalence and risk for a broad spectrum of GI disorders and malignancies among a large sample of inpatients with SSc in the United States, utilizing a nationwide database. 


\section{Materials and methods}

The data used in this study were drawn from the Healthcare Cost and Utilization Project (HCUP) sponsored by the Agency for Healthcare Research and Quality (AHRQ). HCUP combines data from state organizations, hospital associations, private data organizations and the federal government to create a national information resource consisting of patient-level healthcare data. The largest collection of longitudinal hospital care data in the United States is included in HCUP. The HCUP database represents $96 \%$ of the U.S. population and includes over 32 million observations. HCUP consists of multiple databases; however, the database used in this study was the Nationwide Inpatient Sample (NIS) for the years 2010 and 2011, which includes $15,824,031$ patients. This database has inpatient data from over 1000 hospitals and up to 44 states in the United States.

The study included individuals who were at least 18 years of age and had an ICD-9 diagnosis code for SSc. The NIS database allows up to 25 diagnoses per patient. Controls were excluded if they had one or more ICD-9 diagnosis codes for over 100 different autoimmune diseases or were under the age of 18 . SSc patients and controls were randomized and matched by age and sex. Four controls were matched to each SSc patient (13,633 SSc and 54,532 controls).

The comorbid conditions used in this analysis totaled 25 and were variables included in the NIS database obtained from the AHRQ comorbidity software. This comorbidity software assigns variables that identify comorbidities in discharge records using ICD-9-CM codes.

\section{Statistical analysis}

All statistical analyses were conducted using SAS version 9.2 (SAS Institute, Cary, NC). Frequency distributions between categorical variables were assessed using the $\chi^{2}$ test.
An odds ratio with 95\% confidence interval was calculated for each variable. Logistic regression models were used to compare patients with and without SSc for 25 different comorbidities. The survey logistic procedures were used in this analysis to include the weight variable provided in the database. The presence of SSc was used as the dependent variable in these models. Each model was weighted and controlled for the comorbid condition as well as race and urban/rural location. A P-value of $<0.05$ was considered statistically significant.

\section{Results}

Between 2010 and 2011, there were 13,633 admissions with SSc listed as principal diagnosis (5\%) or secondary diagnosis (95\%) for admission (Table 1). The majority of patients admitted were white females admitted to hospitals in urban locations. In each year, patients admitted with SSc as principal diagnosis were significantly younger than patients admitted with SSc as secondary diagnosis.

Table 2 shows the baseline characteristics of SSc patients and controls. Comparisons of demographic variables for SSc patients and controls revealed equal distributions for age and sex. On the other hand, there were significantly more blacks among the SSc group. The SSc group also had more admissions to hospitals in urban locations.

Table 3 shows a list of the frequency of the GI manifestations among SSc and non-SSc patients. The prevalence of GI manifestations included in our analysis was 59.24\% among SSc patients compared to $29.96 \%$ among non-SSc $(\mathrm{P}<0.0001)$. Esophageal reflux constituted the major GI manifestation experienced by SSc patients, with a prevalence of $34.8 \%$ compared to $15.4 \%$ in the control group $(\mathrm{P}<0.0001)$. Other significantly elevated GI manifestations in SSc patients included dysphagia ( $4.3 \%$ vs. $1.9 \%, \mathrm{P}<0.0001)$, esophageal reflux (34.8\% vs. $15.4 \%, \mathrm{P}<0.0001)$, Barrett's esophagus $(1.7 \%$ vs. $0.3 \%, \mathrm{P}<0.0001)$, constipation ( $6 \%$ vs. $4.6 \%, \mathrm{P}<0.0001)$,

Table 1 Hospital admissions with systemic sclerosis (SSc) as principal or secondary diagnosis by demographics and year of admission

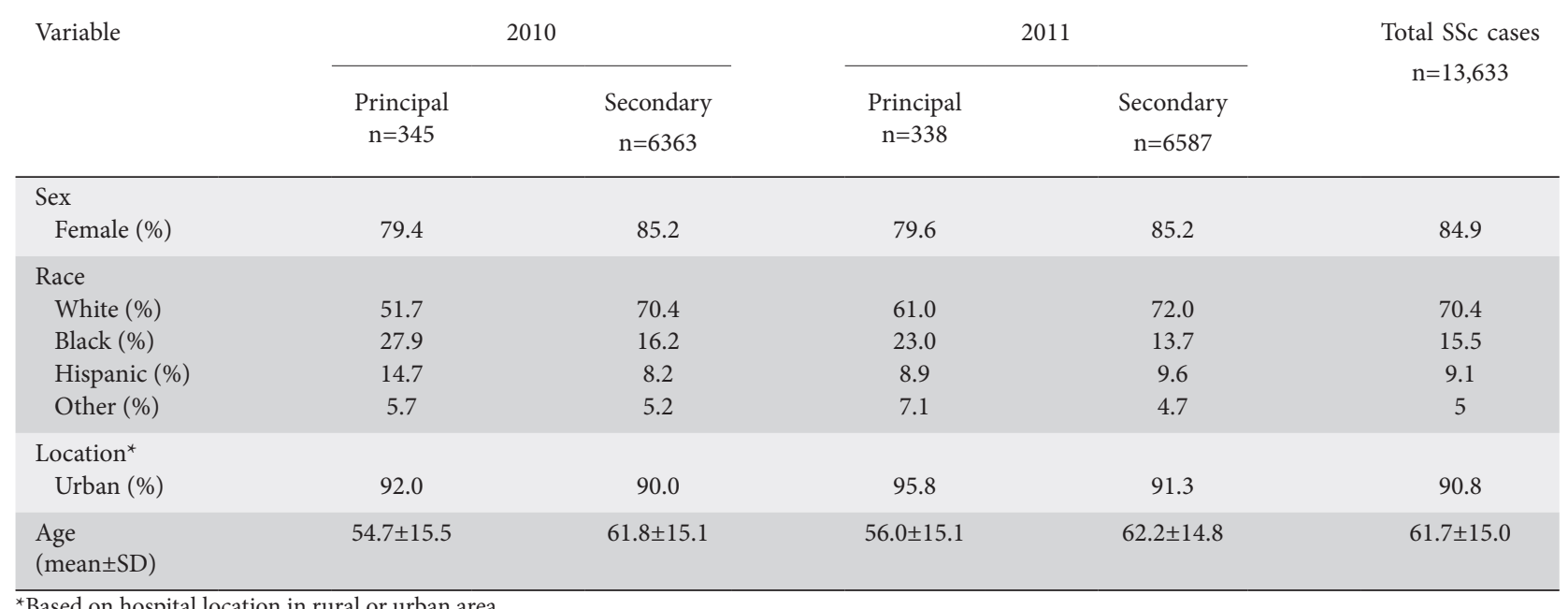


diarrhea ( $4.5 \%$ vs. $2.4 \%, \mathrm{P}<0.0001)$, fecal incontinence $(0.4 \%$ vs. $0.2 \%, \mathrm{P}<0.0001)$, and celiac disease $(0.2 \%$ vs. $0 \%, \mathrm{P}<0.0001)$. On the other hand, cholelithiasis was found to be significantly less common in SSc patients $(1.6 \%$ vs. $2.1 \%, \mathrm{P}<0.0001)$. There was no significant association between SSc and diverticulosis, peptic ulcer disease or other gallbladder diseases.

Table 2 Distribution of systemic sclerosis (SSc) and non-SSc in relation to demographic variables

\begin{tabular}{lccc}
\hline Variable & $\begin{array}{c}\text { SSc } \\
\text { N=13,633 }\end{array}$ & $\begin{array}{c}\text { Non-SSc } \\
\text { N=54,532 }\end{array}$ & P-value \\
\hline Sex & & & \\
$\quad$ Female (\%) & 84.9 & 84.9 & - \\
Age & $61.7 \pm 15.0$ & $61.9 \pm 15.9$ & 0.1524 \\
(mean \pm SD) & & & \\
Race & & & \\
$\quad$ White (\%) & 70.4 & 71.1 & 0.0002 \\
$\quad$ Black (\%) & 15.5 & 14.0 & \\
Hispanic (\%) & 9.1 & 9.6 & \\
$\quad$ Other (\%) & 5.0 & 5.3 & \\
$\quad$ Location* & & & \\
$\quad$ Urban (\%) & 90.8 & 86.6 & $<0.00001$ \\
\hline
\end{tabular}

${ }^{*}$ Based on hospital location in rural or urban area
Table 4 lists the frequencies of a broad spectrum of GI malignancies among SSc and non-SSc patients. Total GI malignancies were found to be significantly lower in SSc patients $(1 \%$ vs. $2.2 \%, \mathrm{P}<0.001)$. Analysis by type of cancer showed significantly lower frequency of colon $(0.2 \%$ vs. $0.8 \%$, $\mathrm{P}<0.001)$, liver ( $0.1 \%$ vs. $0.3 \%, \mathrm{P}<0.001)$, and pancreatic cancers $(0.1 \%$ vs. $0.4 \%, \mathrm{P}<0.001)$ among the $\mathrm{SSc}$ patients compared to the control group. No significant difference between groups was seen in other GI malignancies, including esophageal, gastric and gallbladder malignancies.

\section{Discussion}

This study aimed to examine the prevalence of GI manifestations among SSc patients, based on hospital admissions data, and also to investigate the association between GI manifestations and SSc compared to controls. The prevalence of GI manifestations among SSc patients included in our analysis was $44.4 \%$, and was significantly higher compared to $26.6 \%$ among non-SSc. GI manifestations are known to be significantly more common in SSc patients [4]. The estimated prevalence of GI manifestations has been

Table 3 Distribution of selected gastrointestinal disorders between patients with and without systemic sclerosis (SSc)

\begin{tabular}{|c|c|c|c|c|}
\hline Disorder & $\begin{array}{c}\text { SSc } \\
\text { N (\%) }\end{array}$ & $\begin{array}{c}\text { Non-SSc } \\
\text { N (\%) }\end{array}$ & $\begin{array}{c}\text { OR } \\
95 \% \mathrm{CI}\end{array}$ & P-value \\
\hline Diverticulosis & $556(4.1)$ & $2049(3.8)$ & $\begin{array}{c}1.09 \\
0.99-1.20\end{array}$ & 0.085 \\
\hline Celiac & $34(0.2)$ & $0(0.0)$ & $-*$ & $<0.0001$ \\
\hline Peptic ulcer & $71(0.5)$ & $243(0.4)$ & $\begin{array}{c}1.18 \\
0.91-1.54\end{array}$ & 0.276 \\
\hline Dysphagia & $584(4.3)$ & $1026(1.9)$ & $\begin{array}{c}2.36 \\
2.13-2.62\end{array}$ & $<0.0001$ \\
\hline Fecal incontinence & $53(0.4)$ & $96(0.2)$ & $\begin{array}{c}2.19 \\
1.57-3.08\end{array}$ & $<0.0001$ \\
\hline Constipation & $822(6.0)$ & $2506(4.6)$ & $\begin{array}{c}1.34 \\
1.23-1.45\end{array}$ & $<0.0001$ \\
\hline Diarrhea & $620(4.5)$ & $174(2.4)$ & $\begin{array}{c}14.88 \\
12.57-17.63\end{array}$ & $<0.0001$ \\
\hline Esophageal reflex & $4743(34.8)$ & $8424(15.4)$ & $\begin{array}{c}2.93 \\
2.81-3.05\end{array}$ & $<0.0001$ \\
\hline Barrett's esophagus & $232(1.7)$ & $174(0.3)$ & $\begin{array}{c}5.41 \\
4.44-6.59\end{array}$ & $<0.0001$ \\
\hline Cholelithiasis & $214(1.6)$ & $1128(2.1)$ & $\begin{array}{c}0.75 \\
0.64-0.87\end{array}$ & 0.0002 \\
\hline Other gallbladder diseases & $147(1.1)$ & $517(0.9)$ & $\begin{array}{c}1.14 \\
0.95-1.37\end{array}$ & 0.166 \\
\hline Total & $8076(59.24)$ & $16337(29.96)$ & $\begin{array}{c}3.4 \\
3.27-3.53\end{array}$ & $\begin{array}{c}< \\
0.0001\end{array}$ \\
\hline
\end{tabular}

${ }^{*}$ Not calculable

OR, odds ratio; CI, confidence interval 
Table 4 Distribution of gastrointestinal malignancies between patients with and without systemic sclerosis (SSc)

\begin{tabular}{|c|c|c|c|c|}
\hline Malignancy & $\begin{array}{c}\text { SSc } \\
\text { N (\%) }\end{array}$ & $\begin{array}{l}\text { Non-SS } \\
\text { N (\%) }\end{array}$ & $\begin{array}{c}\text { OR } \\
95 \% \text { CI }\end{array}$ & P-value \\
\hline Oropharyngeal & $2(0.01)$ & $6(0.01)$ & $\begin{array}{c}1.3 \\
0.27-6.61\end{array}$ & 0.72 \\
\hline Oral & $14(0.1)$ & $66(0.1)$ & $\begin{array}{c}0.85 \\
0.48-1.51\end{array}$ & 0.576 \\
\hline Esophageal & $23(0.2)$ & $64(0.1)$ & $\begin{array}{c}1.44 \\
0.89-2.32\end{array}$ & 0.135 \\
\hline Stomach & $16(0.1)$ & $99(0.2)$ & $\begin{array}{c}0.65 \\
0.38-1.09\end{array}$ & 0.1 \\
\hline Small intestine & $1(0.0)$ & $23(0.0)$ & $\begin{array}{c}0.17 \\
0.02-1.29\end{array}$ & 0.086 \\
\hline Colon & $28(0.2)$ & $417(0.8)$ & $\begin{array}{c}0.27 \\
0.18-0.39\end{array}$ & $<0.0001$ \\
\hline Rectum & $31(0.2)$ & $168(0.3)$ & $\begin{array}{c}0.74 \\
0.5-1.08\end{array}$ & 0.12 \\
\hline Liver & $11(0.1)$ & $145(0.3)$ & $\begin{array}{c}0.3 \\
0.16-0.56\end{array}$ & $<0.0001$ \\
\hline Gallbladder & $4(0.02)$ & $32(0.1)$ & $\begin{array}{c}0.45 \\
0.18-1.41\end{array}$ & 0.191 \\
\hline Pancreas & $17(0.1)$ & $197(0.4)$ & $\begin{array}{c}0.34 \\
0.21-0.57\end{array}$ & $<0.0001$ \\
\hline Peritoneum & $3(0.01)$ & $49(0.1)$ & $\begin{array}{c}0.24 \\
0.08-0.79\end{array}$ & 0.018 \\
\hline Other gastrointestinal location & $0(0.0)$ & $9(0.01)$ & $\begin{array}{c}0.21 \\
0.01-3.62\end{array}$ & 0.282 \\
\hline
\end{tabular}

OR, odds ratio; CI, confidence interval

reported to be approximately $70-90 \%[3,4]$. However, one study that investigated the frequency of GI symptoms based on a multi-symptom questionnaire suggested that, in reality, a much higher percentage of patients than expected $(98.9 \%$, i.e. nearly all) suffer from GI symptoms, regardless of the stage of their disease [5].

In this study, we found a significantly higher prevalence of gastroesophageal reflux disease, Barrett's esophagus and dysphagia in patients with SSc, consistent with the current knowledge regarding esophageal involvement in SSc. Esophageal involvement is the most common GI involvement in SSc patients, with an incidence that varies from $70-90 \%$ depending upon the technique of detection [6-8]. These manifestations are related to a weakened lower esophageal sphincter and altered peristaltic activities, secondary to fibrosis and abnormalities in smooth muscle function, that occur in SSc patients $[9,10]$.

Our study also showed a significantly higher prevalence of constipation in SSc patients. Colonic dysmotility in patients with SSc could explain the higher risk of constipation. We also found a significant association with diarrhea and fecal incontinence. These colonic manifestations were evaluated by Trezza et al [11] in a case-series study involving 83 participants. They reported that $20 \%$ of SSc patients have colorectal dysfunction resulting in some or major restriction of social activities or the quality of life [11]. The colonic manifestations included in their analysis were diarrhea, constipation, and fecal incontinence.

One of the other colonic manifestations examined in this study was colonic diverticulosis. Our analysis found no significant association between SSc and colonic diverticulosis. Heinz et al described a characteristic roentgenological appearance of wide-mouth diverticula typical of SSc, found in 9 of 19 cases who had a barium enema examination [12]. Our results suggest that this finding could be random among patients with SSc compared to controls, or it may be underdiagnosed.

We found that patients with SSc have a significantly higher prevalence of celiac disease than controls. The association between celiac disease and SSchas been evaluated in a few studies in the literature. In addition to some case reports $[13,14]$, we identified three studies that discussed this association, though with non-consistent results. Two studies reported a higher prevalence of celiac disease in SSc patients (7-8\%) compared to the general population (1\%). These two studies were limited by small sample sizes $(n=30$ and $n=50)[15,16]$. The third study, conducted by Forbess et al, tested 72 SSc patients for celiac disease serology then biopsy [17]. They reported the prevalence of celiac antibodies in SSc population as 3/72 (4\%), but no cases of celiac disease confirmed by biopsy were seen in 
their SSc cohort [17]. They also found no important differences with respect to GI symptoms in the celiac antibody-positive compared with antibody-negative SSc patients. Given these inconsistent results and the small sample sizes in the three previous studies, there was a need for a large comparative study to detect any difference between the two groups. Our study is the largest observational comparative study to evaluate the association between celiac disease and SSc. Celiac disease is known to be associated with an increased risk of multiple autoimmune disorders in patients and their relatives [18-20].

In this study we found that there was no significant difference in gallbladder diseases between SSc patients and controls. Regarding cholelithiasis, it was significantly lower in SSc patients compared to controls. Two studies in the literature showed that gallbladder motility in patients with SSc was not significantly reduced when compared to controls [21,22], consistent with our findings.

Our study found a significantly lower prevalence of all GI cancers in SSc patients. The risk of all malignancies in SSc is controversial. Some studies have suggested that these patients have an increased total risk of malignancies compared to the general population, which, in most cases, was attributable to lung cancer, with a non-consistent increase in some other types of malignancy [23-30]. On the other hand, a few other studies showed that there is no difference in the risk of malignancy in patients with SSc compared to the general population [31-34]. One study included GI cancer as a subgroup and showed no significant difference between SSc and the general population in the standardized incidence ratio of all GI malignancies [27].

In our study we found no significant difference in esophageal and oropharyngeal cancer between SSc patients and controls. Esophageal cancer was reported to be more frequent in a subgroup analysis of two studies [28,29], while five other studies showed no significant difference [23,24,30,33-35]. One study reported a higher risk of oropharyngeal cancer in SSc patients [28].

Our analysis showed that the risk of liver cancer was significantly lower in SSc patients. Chatterjee et al [33] found that black females with scleroderma had significantly higher rates of liver cancer, which was not evident in other subgroups. Additionally, two other studies found a higher incidence of liver cancer in SSc patients [29,35]. However, one of these studies reported only one case and the calculated standardized incidence ratio had a wide confidence interval, which calls into question the clinical significance of this finding [29].

Our study has several important strengths. We used a national database representing $96 \%$ of the U.S. population, with over 32 million patients. Of those, 15,824,031 records were screened and used in our analysis, enabling a clear picture of the prevalence of GI problems among SSc patients on a countrywide basis. Furthermore, the GI problems identified in this study were based on doctor-diagnosed diseases and not on self-reporting by patients.

There are also several potential weaknesses in the design of this study. First, the data were limited to hospitalized patients; therefore, not all patients suffering from SSc were investigated. Additionally, HCUP data may not reflect the true prevalence

\section{Summary Box}

\section{What is already known:}

- Gastrointestinal (GI) manifestations are common among patients with systemic sclerosis (SSc)

- Esophagus is the most common GI organ involved in SSc

\section{What the new findings are:}

- Our results emphasize the established association between SSc and esophageal disorders such as dysphagia and reflux disease

- There was a significant positive association between SSc and celiac disease, and a negative association with cholelithiasis and GI malignancies

of GI manifestations, as the database relies on an inpatient coding system. Coding errors would affect the reliability and validity of our results. In addition, the data do not include the level of workup and investigation used to reach the diagnoses code; however, these are physician-based diagnoses, which increases their reliability. Furthermore, because HCUP is limited to hospitalized patients, the SSc patients included in this study was sicker than the other group of SSc patients seen on outpatient setting and were not included in this database, thereby hospitalized patients possibly presented with a higher prevalence of certain types of GI problems the group included in this study was sicker than the SSc patients not requiring hospitalization, thereby possibly presenting with a higher prevalence of certain types of GI problems. Multiple admissions for the same patient might be problematic. However, there is no reason to believe that the pattern of admission differed between the SSc patients and the controls.

In conclusion, GI manifestations are common among patients with SSc. Our results emphasized the established association between SSc and esophageal disorders such as dysphagia and reflux disease. Moreover, our analysis advocated a significant positive association between SSc and celiac disease, and a negative association with cholelithiasis and some GI malignancies. These results could be confirmed by further studies.

\section{References}

1. Mayes MD, Lacey JV Jr, Beebe-Dimmer J, et al. Prevalence, incidence, survival, and disease characteristics of systemic sclerosis in a large US population. Arthritis Rheum 2003;48:2246-2255.

2. Savarino E, Furnari M, de Bortoli N, et al. Gastrointestinal involvement in systemic sclerosis. Presse Med 2014;43 (10 Pt 2):e279-e291.

3. Tian XP, Zhang X. Gastrointestinal complications of systemic 
sclerosis. World J Gastroenterol 2013;19:7062-7068.

4. Thoua NM, Bunce C, Brough G, Forbes A, Emmanuel AV, Denton CP. Assessment of gastrointestinal symptoms in patients with systemic sclerosis in a UK tertiary referral centre. Rheumatology (Oxford) 2010;49:1770-1775.

5. Schmeiser T, Saar P, Jin D, et al. Profile of gastrointestinal involvement in patients with systemic sclerosis. Rheumatol Int 2012;32:2471-2478.

6. Clements PJ, Becvar R, Drosos AA, Ghattas L, Gabrielli A. Assessment of gastrointestinal involvement. Clin Exp Rheumatol 2003;21:S15-S18.

7. Sjogren RW. Gastrointestinal motility disorders in scleroderma. Arthritis Rheum 1994;37:1265-1282.

8. Poirier TJ, Rankin GB. Gastrointestinal manifestations of progressive systemic scleroderma based on a review of 364 cases. Am J Gastroenterol 1972;58:30-44.

9. Gyger G, Baron M. Gastrointestinal manifestations of scleroderma: recent progress in evaluation, pathogenesis, and management. Curr Rheumatol Rep 2012;14:22-29.

10. Treacy WL, Baggenstoss AH, Slocumb CH, Code CF. Scleroderma of the esophagus. A correlation of histologic and physiologic findings. Ann Intern Med 1963;59:351-356.

11. Trezza M, Krogh K, Egekvist H, Bjerring P, Laurberg S. Bowel problems in patients with systemic sclerosis. Scand J Gastroenterol 1999;34:409-413.

12. Heinz ER, Steinberg AJ, Sackner MA. Roentgenographic and pathologic aspects of intestinal scleroderma. Ann Intern Med 1963;59:822-826.

13. GomezGómez-Puerta JA, Gil V, Cervera R, et al. Coeliac disease associated with systemic sclerosis. Ann Rheum Dis 2004;63:104-105.

14. Trucco Aguirre E, Olano Gossweiler C, Méndez Pereira C, Isasi Capelo ME, Isasi Capelo ES, Rondan Olivera M. [Celiac disease associated with systemic sclerosis]. Gastroenterol Hepatol 2007;30:538-540.

15. Luft LM, Barr SG, Martin LO, Chan EK, Fritzler MJ. Autoantibodies to tissue transglutaminase in Sjögren's syndrome and related rheumatic diseases. J Rheumatol 2003;30:2613-2619.

16. Rosato E, De Nitto D, Rossi C, et al. High incidence of celiac disease in patients with systemic sclerosis. J Rheumatol 2009;36:965-969.

17. Forbess LJ, Gordon JK, Doobay K, et al. Low prevalence of coeliac disease in patients with systemic sclerosis: a cross-sectional study of a registry cohort. Rheumatology (Oxford) 2013;52:939-943.

18. Lauret E, Rodrigo L. Celiac disease and autoimmune-associated conditions. Biomed Res Int 2013;2013:127589.

19. Petaros P, Martelossi S, Tommasini A, Torre G, Caradonna M, Ventura A. Prevalence of autoimmune disorders in relatives of patients with celiac disease. Dig Dis Sci 2002;47:1427-1431.

20. Cataldo F, Marino V. Increased prevalence of autoimmune diseases in first-degree relatives of patients with celiac disease. J Pediatr Gastroenterol Nutr 2003;36:470-473.

21. Lock G, Zeuner M, Kammerl M, Lang B, Schölmerich J, Holstege A. Gallbladder motility in systemic sclerosis. Rheumatol Int 1996;16:61-65.

22. Jonderko G, Koterla W, Końca A, et al. [Volume of the functioning gallbladder and its emptying in patients with progressive systemic sclerosis]. Pol Arch Med Wewn 1993;89:298-303.

23. Roumm AD, Medsger TA Jr. Cancer and systemic sclerosis. An epidemiologic study. Arthritis Rheum 1985;28:1336-1340.

24. Rosenthal AK, McLaughlin JK, Linet MS, Persson I. Scleroderma and malignancy: an epidemiological study. Ann Rheum Dis 1993;52:531-533.

25. Abu-Shakra M, Guillemin F, Lee P. Cancer in systemic sclerosis. Arthritis Rheum 1993;36:460-464.

26. Higuchi M, Horiuchi T, Ishibashi N, Yoshizawa S, Niho Y, Nagasawa K. Anticentromere antibody as a risk factor for cancer in patients with systemic sclerosis. Clin Rheumatol 2000;19:123-126.

27. Hill CL, Nguyen AM, Roder D, Roberts-Thomson P. Risk of cancer in patients with scleroderma: a population based cohort study. Ann Rheum Dis 2003;62:728-731.

28. Derk CT, Rasheed M, Artlett CM, Jimenez SA. A cohort study of cancer incidence in systemic sclerosis. J Rheumatol 2006;33:1113-1116.

29. Kang KY, Yim HW, Kim IJ, et al. Incidence of cancer among patients with systemic sclerosis in Korea: results from a single centre. Scand J Rheumatol 2009;38:299-303.

30. Olesen AB, Svaerke C, Farkas DK, Sørensen HT. Systemic sclerosis and the risk of cancer: a nationwide population-based cohort study. Br J Dermatol 2010;163:800-806.

31. Duncan SC, Winkelmann RK. Cancer and scleroderma. Arch Dermatol 1979;115:950-955.

32. Black KA, Zilko PJ, Dawkins RL, Armstrong BK, Mastaglia GL. Cancer in connective tissue disease. Arthritis Rheum 1982;25:1130-1133.

33. Chatterjee S, Dombi GW, Severson RK, Mayes MD. Risk of malignancy in scleroderma: a population-based cohort study. Arthritis Rheum 2005;52:2415-2424.

34. Hashimoto A, Arinuma Y, Nagai T, et al. Incidence and the risk factor of malignancy in Japanese patients with systemic sclerosis. Intern Med 2012;51:1683-1688.

35. Rosenthal AK, McLaughlin JK, Gridley G, Nyrén O. Incidence of cancer among patients with systemic sclerosis. Cancer 1995;76:910-914. 